\title{
How to Get Well-Preserved Samples for Transmission Electron Microscopy
}

\author{
Chang-Hyun Park*, Hyun-Wook Kim, Im Joo Rhyu ${ }^{1}$, Chang-Sub Uhm ${ }^{1}$ \\ Medical Science Research Center, Korea University College of Medicine, Seoul 02841, Korea \\ ${ }^{1}$ Department of Anatomy, Korea University College of Medicine, Seoul 02841, Korea
}

*Correspondence to:

Park $\mathrm{CH}$,

Tel: +82-2-2286-1323

Fax: +82-2-2286-1329

E-mail:kmemno1@empal.com

Received December 1, 2016

Revised December 15, 2016

Accepted December 16, 2016

\begin{abstract}
Proper sample preparation prior to microscopy is necessary for maintaining the components of tissues in a state as close to a living state as possible. For optimal preservation of biological samples, the sampling conditions are as important as the fixation itself. Various factors influence the selection and fixation efficiencies of a fixative, including sample size, osmolarity, $\mathrm{pH}$, penetration rate and depth, fixative temperature, fixation time, fixative concentration, fixative amount, and retention time. Therefore, several factors for selecting and administering fixation procedures are evaluated pertaining to optimal sample preparation for transmission electron microscopy.
\end{abstract}

Key Words: Fixation, Penetration, Fixative

\section{INTRODUCTION}

For the microscopic observation of biological samples, we need to prepare or process samples to the state we want to observe. In most cases we want to know what was happening in the cell or tissue at the time when we removed a small piece, called "sample" from the biological entity. If you fail to maintain the wanted state, you could turn a successful experiment into a failure because of failure in proving the changes in structures through the experiment. In addition, you can fail to interpret the physiological or pathological meaning hidden in the microstructure of the sample. Two processes are especially important to maintain the sample as close to the living state as possible: sampling and fixation.

\section{SAMPLING}

Various biological samples can be observed with a transmission electron microscope (TEM). Samples range from a biopsy specimen obtained from a person for pathological examination to tissues obtained during surgery or autopsy and from an experimental animal. In addition, cultured cells, bacteria, viruses, fungi, plants, and many other biologic organic materials may be observed. The samples should be obtained in accordance with ethical principles. This is especially true for samples obtained from human beings that shall not be used for purposes other than for the initial purpose of their retrieval. For example, tissues collected for pathological diagnosis should be used only for this purpose. If you want to use human samples for research or want to incorporate any data obtained from human samples in research or pathological diagnosis, you need to obtain permission from the donor. You also must obtain permission from the institute, usually from an "Institutional Review Board," for an experimental design requiring human samples. In case of experimental animals, the regulations for the treatment of experimental animals must be abided to. This usually requires permission from the "Laboratory Animal Committee" before commencing the experiment. Although there are no regulations or codes of ethics on plants or microorganisms similar to those applied to human or animal samples, microorganisms often pose a health hazard risk to the experimenter. Therefore, these organisms should be handled according to appropriate management procedures. In general, the technical factors to consider when collecting tissue samples are size, orientation, and sampling time (Hayat,

@ This is an open-access article distributed under the terms of the Creative Commons Attribution Non-Commercial License (http://creativecommons.org/licenses/by-nc/4.0) which permits unrestricted noncommercial use, distribution, and reproduction in any medium, provided the original work is properly cited.

Copyrights @ 2016 by Korean Society of Microscopy 
1973, 1981).

\section{Size}

The size of the tissue samples should be determined considering the purpose of the experiment and the expected range of observation. Technically speaking, the sample should be large and preserved as best as possible to provide a sufficient field of observation and maintain subtle changes by the experimental procedures. Therefore, the size of the tissue sample is primarily determined by how well and fast the fixative infiltrates into the specific tissue to provide optimal tissue preservation (Table 1). It should be noted that smaller sample sizes are also of help when handling the tissue sample. Therefore, a tissue block smaller than $1 \mathrm{~mm}^{3}$ is generally recommended for TEM (Uhm et al., 1998). Reducing the dimensions of the sample to $0.5 \mathrm{~mm}$ can aid in an even and uniform quality of fixation throughout the sample (Romert \& Matthiessen, 1975).

One commonly used method for obtaining thin tissue sections is to cut the tissue on the paraffin plate (dental wax sheets) or parafilm using two razor blades put in the form of an "X." You can hold down the tissue under one blade of the "X," and pull the other blade to the side for obtaining thin slices without any no special tools. For circumstances where the thickness of the tissue slice must be uniform, as for immunohistochemistry, special tools such as a vibratome, tissue chopper, and hand microtome are recommended (Smith, 1970). In addition, you can apply a simple coverslip or glass slide to obtain a thin tissue but considerable practice for this is required (Lewis \& Knight, 1977).

In cases where the size of the tissue is too large, different parts of the tissue may be fixed to different degrees (Fig. 1). The surface may be over fixed due to excessive exposure to the fixative. Over fixation makes the tissue hard and brittle, thereby allowing easy tissue damage during handling. In this case, tissue components can leak out through the damaged part, resulting in structural changes to the cell and cellular architecture. In addition, in case of larger tissues, the center of the tissue block may be under fixed due to the poor penetration of the fixative. The under-fixed areas may have undergone autolysis before fixation. Because autolysis destroys the ultrastructure of cells, structural details cannot be

Table 1. Fixation ranges corresponding to rapid fixation depending on the constituents of the fixative

\begin{tabular}{lcc}
\hline \multicolumn{1}{c}{ Types of fixing solution } & $\begin{array}{c}\text { Fast fixation range } \\
(\mathrm{mm})\end{array}$ & $\begin{array}{c}\text { Maximum size of } \\
\text { tissues }(\mathrm{mm})\end{array}$ \\
\hline Osmium tetroxide & $\sim 0.25$ & 0.5 \\
$2.5 \%$ glutaraldehyde & $\sim 0.13$ & 0.25 \\
Mixture of glutaraldehyde & $\sim 0.5$ & 1.0 \\
and paraformaldehyde & & \\
\hline
\end{tabular}

preserved to observe. Optimal fixation is the most important part to ensure that tissues have minimal deformation prior to observation under an electron microscope. Careful attention must be paid to avoid over fixed or under-fixed areas of tissue. In either case, cellular or tissue deformation by improper fixation may be mistakenly interpreted to have resulted from the experiment (Hayat, 1981).

\section{Sample Orientation}

If it is necessary to distinguish as to which side is close to the surface as in the cerebral cortex or which part is proximal to the peripheral nerve or muscle, you may cut the tissue like a pillar or cut out the ear canal. This may reduce the confusion.

\section{Elapsed Time for Sampling}

It is most desirable to collect the tissue while the animal or organ is still alive. If this is not possible, the sample should be obtained as immediately as possible after death. Sometimes, fixation prior to sample acquisition is recommended. Perfusion fixation is recommended for various tissues and organs, including the brain, spinal cord, and tissues located deep within the body that take more time for collection, show a tendency toward rapid decay, and inherently prevent the penetration of fixatives; for example, in the lung, air prevents a fixative from infiltrating. Sometimes, organs may be submersed in the fixative or you may inject a small amount of dye containing a fixative before sampling. In any case, the harvested tissue must be rapidly cut into an appropriate size and immersed in a fixative.

\section{FIXATION}

Fixation is the first step in tissue processing for preserving a cell or tissue in a state as similar as possible to its living state. Fixation has several purposes: 1 . to maintain the cells and tissue components with minimal deformation compared to their living state. Fixation prevents autolysis, prevents decay by bacteria, and suppresses changes in volume and shape; 2 . to make the tissue hard and strong enough to minimize damage

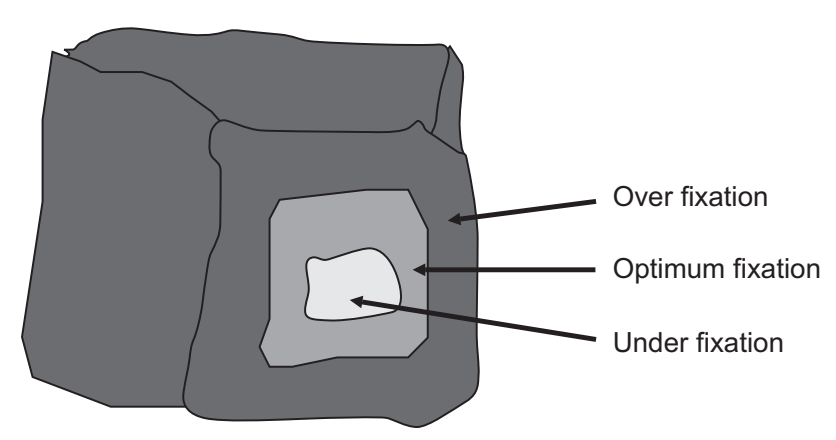

Fig. 1. Differences in fixation depending on sample thickness. 
and reduce deformation during dehydration, embedding, and sectioning following fixation; and 3. to make the sample suitable for observation under an electron microscope, which requires that cells and tissues be stained prior to observation and can only be achieved on fixed cells and tissue. In addition fixation makes the sample durable and resistant to damage when exposed to the electron beam.

Chemical fixation is the most commonly used method to achieve the aforementioned state of fixation. It is a chemical process to prevent tissue destruction or deformation by the reaction between the chemical groups of the tissue and fixative. Some limitations include the following: 1. It cannot prevent the loss or transformation of some tissue components; 2. Some biological characteristics of the tissue components, such as enzyme activity, antigenicity, and other biological functions, are often altered; and 3. different degrees of fixation among tissue components may lead to a change in the three-dimensional architecture of the tissue and/or cell. Such limitations can be avoided through cryofixation, which suppresses the chemical reactions in chemical fixation by rapid freezing. However, this require special equipment. In this paper, we will discuss the principle and method of chemical fixation, because it is still the most widely used method for tissue fixation. Fixatives can be delivered to the tissue of interest in two ways. The first method is called "immersion fixation," wherein the tissues are cut into small pieces, put into the fixative, and left until the tissue is fixed. The other method is to circulate a fixative through the blood vessels. This is termed as "perfusion fixation" and is the preferred method for fixation of small laboratory animals or tissues that undergo rapid lysis after removal. Perfusion pressure should be adjusted according to the blood pressure of the sampling tissue.

\section{Factors Affecting Selection and Application of Fixatives}

Various factors should be taken into consideration to select an optimal fixative. These factors include the following: 1. consideration of the purpose of the study, materials of interest, practical applicability, sample size, etc.; 2 . fixatives that minimize shrinkage or expansion of the tissue and rapidly penetrate into the tissue; 3 . fixatives that are easy to handle; and 4. proper buffering of the fixative to maintain an appropriate osmolarity and $\mathrm{pH}$ of laboratory animals.

Factors affecting fixation include the following: the size of the specimen, as discussed, and osmolarity. Osmolarity determines the flow of water into or out of the tissue to make the concentration of solutes equal in both sides. Such movement of water results in deformations such as shrinkage or expansion and even promotes the destruction of cells (Saito \& Tanaka, 1980). The optimal osmolarity of fixatives is different between organisms and tissues. Also, the effective osmolarity that affects the semipermeable membrane of cells is more significant in considering the effect of osmolarity in fixation. Although the osmolarity of a fixative can be measured using an osmometer, it is rare to have an osmometer in a conventional electron microscope laboratory. Therefore, it is helpful to remember the osmolarity of some important fixative components and calculate the total osmolarity (Table 2).

It is recommended to make fixative for mammalian tissues with a total osmolarity of approximately of 500 700 mosmoles. At this total osmolarity, the effective osmolarity is most similar to that of living organisms. For reference, the total osmolarity for soft tissues such as embryos is 300, 400 mosmoles.

One of the most commonly used fixatives, $2.5 \%$ glutaraldehyde in $0.1 \mathrm{M}$ phosphate buffer, has an osmolarity of about 450 mosmoles. The glutaraldehyde contributes approximately 250 mosmoles and the phosphate buffer contributes about 200 mosmoles. To increase the osmolarity, saccharose or tannic acid can be added to the fixative. In this case, $1 \%$ of added saccharose provides approximately 100 mosmoles. Because this is only a rough guide, it is recommended to test various fixatives in advance to identify the most suitable fixing solution at the optimal osmolarity.

\section{pH}

When the cells die during the fixation process, the contents of the lysosome are released and the $\mathrm{pH}$ of the tissue becomes acidic, accelerating the destruction of macromolecules in the tissue. For this reason, the optimal $\mathrm{pH}$ should be maintained. In particular, $\mathrm{pH}$ is important when using glutaraldehyde or osmium alone, which has poor penetration. Because the average $\mathrm{pH}$ of most animal cells is 7.4 (cytoplasm, 7.0; nucleolus, 7.6), it is recommended to adjust the $\mathrm{pH}$ of the fixative to 7.2 7.4. In invertebrates and embryos, the $\mathrm{pH}$ of the fixative is preferably $8.0 \sim 8.4$. In case of plant cells, the $\mathrm{pH}$ of the cytoplasm is $6.8 \sim 7.1$ and that of the vascular sap is $\mathrm{pH}$ 5.0 6.0. Therefore, the $\mathrm{pH}$ of the vascular sap during initial fixation should be maintained at 8.0.

If fixations are sequentially performed using different fixatives, samples should be thoroughly washed with the same buffers used in the fixative to prevent chemical reactions among fixatives. This principle applies during prefixation using aldehydes and following postfixation using osmium. Commonly used buffers for electron microscopy are phosphate and cacodylate buffers. However, various other buffers can be used according to the purpose of experiment.

Table 2. Osmolarities of commonly used fixative and buffer solutions

\begin{tabular}{lc}
\hline Types of fixative and buffer solutions & Osmolarity (mOsmole) \\
\hline 0.2 M cacodylate buffer & 350 \\
0.2 M Sorensen's phosphate buffer & 400 \\
1\% pure glutaraldehyde & 100 \\
1\% osmium tetroxide & 40 \\
\hline
\end{tabular}


Table. 3. Penetration depth of various fixative solutions in human liver tissue

\begin{tabular}{lcc}
\hline Types of buffered fixative & $\begin{array}{c}\text { Penetration depth } \\
\text { after } 4 \mathrm{~h}(\mathrm{~mm})\end{array}$ & $\begin{array}{c}\text { Penetration depth } \\
\text { after 24 } \mathrm{h}(\mathrm{mm})\end{array}$ \\
\hline 5\% paraformaldehyde & 2.5 & 10.0 \\
3\% glutaraldehyde & 0.5 & 1.1 \\
2\% osmium tetroxide & 0.8 & 1.4 \\
\hline
\end{tabular}

\section{Penetration Speed and Depth}

Different fixatives penetrate into the tissue at different speeds (Table 3). In general, the penetration rate is higher at higher temperatures. In addition, if the concentration is higher, if the sample is kept for long, or if perfusion fixation is used, the fixative will penetrate deeper into the tissue.

\section{Temperature}

Temperature influences the degree of tissue destruction and deformation. In general, fixation is performed at a low temperature $\left(0^{\circ} \mathrm{C} \sim 4^{\circ} \mathrm{C}\right)$ to prevent self-dissolution or extraction. In this case, longer fixation time is required than that at room temperature. In some cases, temperature is adjusted for special purposes. For example, fixation with glutaraldehyde at $37^{\circ} \mathrm{C}$ tends to promote the extraction of liquid components of the cytoplasm, including the cellular skeleton and action filaments.

\section{Fixation Time}

Time for adequate fixation is determined based on the size of the tissue, the fixative to be used, the temperature, etc. Usually fixation takes $2 \sim 4 \mathrm{~h}$ and postfixation procedures take $30 \mathrm{~min}$.

\section{Concentration}

The concentration is determined by considering $\mathrm{pH}$ or osmolarity, as discussed above. Usually, $2 \%$ glutaraldehyde in $0.1 \mathrm{M}$ cacodylate (phosphate) buffer, $\mathrm{pH} 7.2 \sim 7.4$, is used for animal tissues. Glutaraldehyde can be used at 2\% 5\% and osmium at $1 \% \sim 2 \%$ without adverse effects.

\section{Amount}

The amount of the fixative is generally recommended to be 20 50 times of the volume of the tissue.

\section{Storage Time}

It is good to process the tissue right after optimal fixation to prevent overfixation; however, there are cases when the samples will be needed for a long time, and thus, it may be necessary to preserve the tissue for an extended time. In such cases, it is recommended to thoroughly wash out the remaining fixatives thoroughly with the same buffer used to make the fixative, and preserve the fixed sample in newly made fresh fixative. Although the exact mechanism of action is unknown, using this process, minimal deformation due to overfixation is observed.

\section{MECHANISM OF ACTION OF FIXATIVES}

In general, either $2 \%$ paraformaldehyde or $2 \%$ glutaraldehyde is used for prefixation, and $1 \% \sim 2 \%$ osmium tetroxide is used for postfixation. Because paraformaldehyde tends to make the sample brittle, only glutaraldehyde is used for scanning electron microscopy (SEM). Osmium tetroxide is used postfixation both TEM and SEM to stabilize the tissue and improve the electron density or conductivity (Bozzola \& Russell, 1992).

The mechanism of action of the main components of the fixative is as follows: 1. Osmium tetroxide unsaturated bonds such as double bonds. Therefore it is mainly used to fix lipid, the main constituent of the cell membrane. Osmium changes the unsaturated fatty acids in lipid to stable glycol osmate. A molecule of osmium tetroxide can bind two molecules of fatty acids. In addition, denatured nucleic acids and proteins rich in amino acids with unsaturated double bonds, such as cysteine and tryptophan also react with osmium. Osmium's ability to fixate and to contrast after fixation is determined by the degree of unsaturation, the lipid and the protein appears differently. Fat droplets show different degrees of electron density due to the different amounts of unsaturated fats. Osmium has been independently used because it is an excellent fixative with sufficient contrast under the electron beam. Recently, it has been used as a postfixative after aldehyde fixation. It should be noted that osmium is very toxic and it is rapidly absorbed through the respiratory tract and skin. 2. Formaldehyde has one aldehyde group ( $\mathrm{H}-\mathrm{CHO})$, which crosslinks with proteins, nucleic acids, and lipids. In case of proteins, two $\mathrm{NH}_{2}$ groups react with aldehyde groups to form insoluble methyl bridges $\left(-\mathrm{CH}_{2}-\right)$. The mechanism of the reaction with lipids and nucleic acids is not well known and reacts poorly to polysaccharides and mucosubstances. Formaldehyde used for fixing tissues for optical microscopy is called formalin, which is sold as a $40 \%$ stock solution (containing 12\% 15\% methanol). Thus, the actual formaldehyde concentration of $10 \%$ buffered neutral formalin used for light microscopy is $4 \%$.

For electron microscopy, purified paraformaldehyde is used. Paraformaldehyde rapidly penetrates because it has only one aldehyde group to react. In addition, it generally penetrates deeper and faster, but has a relatively weak fixation power and insufficient contrast. Therefore, to obtain better fixation and proper contrast, the tissues fixed with formaldehyde are often postfixed with osmium tetroxide. As noted above, it is recommended to wash out the paraformaldehyde with the same buffer used before osmium fixation. 3. Glutaraldehyde is a dialdehyde $\left(\mathrm{OHC}-\mathrm{CH}_{2}-\mathrm{CH}_{2}-\mathrm{CH}_{2}-\mathrm{CHO}\right)$ in which two aldehydes are present at both ends of the molecule. It 
is a cross-linking fixative like formaldehyde; therefore it shows weak fixing power against lipids, polysaccharides, and mucosubstances. For example, approximately $65 \%$ of glycogen in tissues is preserved after glutaraldehyde fixation. However, it binds strongly with proteins having two aldehyde groups. In particular, the amino acid lycine, tyrosine, tryptophan, and phenylalanine show a strong binding affinity to glutaraldehyde. This reaction is influenced by $\mathrm{pH}$. Polymerization of proteins by glutaraldehyde is accelerated at $\mathrm{pH} 8.0$ and the permeability into the tissue is impaired at $\mathrm{pH}$ 6.5. Glutaraldehyde is an excellent fixative for preserving the microstructure of cells and tissue; however, like paraformaldehyde, it does not have enough contrast and does not stain tissue components. Also, because it has almost no power to fix lipid components, proteins mixed with lipids, as in the membrane, cannot be preserved intact during the organic solvent treatment. Therefore, postfixation should be performed using osmium tetroxide.

\section{PRECAUTIONS WHEN HANDLING FIXATIVE}

Fixative can easily damage the eyes, mucous membranes, and airways and should be handled with care. Osmium tetroxide, in particular, should be handled with vinyl gloves and a mask in a safety hood because it vaporizes, evaporates easily, and is absorbed through the skin. Osmium tetroxide is usually sold as a $1 \mathrm{~g}$ crystal in a brown glass container. Because it does not easily dissolve, its dissolution should be initiated at least 1 day before use. It should be kept in a brown bottle at a low temperature to prevent exposure to the light and potential of evaporation. In recent years, a commercially available $4 \%$ solution in an ampule has become available. The used fixative should be stored in a separate waste container and should be kept in a safe place until it is disposed of in accordance with the waste disposal regulations.

\section{SUMMARY}

In this technical review, we examined factors that affect the fixation process for electron microscopy from sampling to chemical fixation. The most important aspect to consider for handling biological specimens is how to maintain the ultrastructures as close to a living state as possible. All the factors, including the size of the sample, osmolarity, $\mathrm{pH}$, penetration speed, penetration depth, temperature, fixation duration, chemical components, concentration, fixative amount, and storage duration must be considered to achieve fixation.

\section{CONFLICT OF INTEREST}

No potential conflict of interest relevant to this article was reported.

\section{REFERENCES}

Bozzola J J and Russell L D (1992) Electron Microscopy (Jones and Bartlett Publishers, Boston).

Hayat M A (1973) Principles and Techniques of Electron Microscopy. Biological Applications (Van Nostrand Reinhold Co., New York, etc.).

Hayat M A (1981) Fixation for Electron Microscopy (Academic Press, New York).

Lewis P P and Knight D P (1977) Staining Methods for Sectioned Material. In: Practical Methods in Electron Microscopy (North-Holland Publ., Amsterdam).

Romert P and Matthiessen M E (1975) Fixation of foetal pig liver for electron microscopy. I. The effect of various aldehydrs and of delayed fixation. Anat. Embryol. 147, 243-258.

Saito $Y$ and Tanaka $Y$ (1980) Glutaraldehyde fixation of fish tissues for electron microscopy. J. Electron Microsc. 29, 1-7.

Smith R E (1970) Comparative evaluation of 2 instruments and procedures to cut nonfrozen sections. J. Histochem Cytochem. 18, 590-591.

Uhm C S, Park E K, and Park C H (1998) Tissue preparation with t-Butyl alcohol freeze-drying method for scanning electron microscopy: application for rat liver. Korean J. Electron Microsc. 28, 299-306. 